Wesleyan University

From the SelectedWorks of Charles A. Sanislow, Ph.D.

Summer 2000

Short and long-term effects of medication and psychotherapy in the brief treatment of depression: Further analyses of data from the NIMH TDCRP

Sidney J. Blatt, Yale University

David C. Zuroff, McGill University

Colin M. Bondi, Yale University

Charles A. Sanislow, Yale University 
Psychotherapy Research 10(2) 215-234, 2000

(1)2000 Society for Psychotherapy Research

\title{
SHORT-AND LONG-TERM EFFECTS OF MEDICATION AND PSYCHOTHERAPY IN THE BRIEF TREATMENT OF DEPRESSION: FURTHER ANALYSES OF DATA FROM THE NIMH TDCRP
}

\author{
Sidney J. Blatt \\ Yale University \\ David C. Zuroff \\ McGill University \\ Colin M. Bondi \\ Charles A. Sanislow III \\ Yale University
}

\begin{abstract}
Prior analyses of data from the NIMH sponsored Treatment for Depression Collaborative Research Program (TDCRP; e.g., Elkin, 1994) indicated greater reduction of symptoms at midtreatment (eighth week) with Imipramine (IMI-CM) than with Cognitive-behavioral therapy (CBT) and Interpersonal therapy (IPT), but no significant differences in symptom reduction among these three active treatments at termination. Current analyses of previously unanalyzed data from ratings by therapists, clinical evaluators, and patients at termination and at 18-month follow-up also indicated no significant differences among these treatments in symptom reduction or ratings of current dinical condition. But significant treatment differences emerged at the 18-month follow-up in patients' ratings of the effects of treatment on their life adjustment. Patients in IPT reported greater satisfaction with treatment, and patients in both IPT and CBT reported significantly greater effects of treatment on their capacity to establish and maintain interpersonal relationships and to recognize and understand sources of their depression than did patients in IMI-CM or placebo.
\end{abstract}

The Treatment of Depression Collaborative Research Program (TDCRP), sponsored by the National Institute of Mental Health (NIMH), compared two forms of btief psychotherapy for the treatment of depression-Cognitive-behavioral therapy (CBT) and Interpersonal therapy (IPT)--with Imipramine plus clinical management (IMT$\mathrm{CM}$ ), as a standard reference condition, and with pill placebo plus clinical management (PLA-CM) as a double-blind control (Elkin et al., 1989). Clinical management consisted of nonspecific supportive interactions lasting 20-30 minutes (Elkin, Parloff, Hadley, \& Autry, 1985). In a carefully controlled three-by-four factorial design, 239 outpatients with major depression were randomly assigned to one of four treatments

Correspondence regarding this anticle should be addressed to Sidney J. Blatt, Room 612,25 Park Street, New Haven, CT 06519. Telephone: 203-785-2090; fax: 203-785-7357; E-maii: Sidney.Blart@yale.edu. 
across three sites. Treatments were compared at termination (after 16 weeks of treatment) for symptomatic improvement on four primary measures - two interview rating scales: the Hamilton Rating Scale for Depression (HRSD; Hamilton, 1960, 1967) and the Global Adjustment Scale (GAS; Endicott, Spitzer, Fleiss, \& Cohen, 1976); and two self-report measures: the Hopkins Symptom Checklist (HSCL-90; Derogatis, Lipman, \& Covi, 1973) and the Beck Depression Inventory (BDI; Beck \& Beamesderfer, 1974; Beck, Ward, Mendelsohn, Mock, \& Erbaugh, 1960). Summarizing these analyses, Elkin, Gibbons, Shea, and Shaw (1996, p. 93) concluded that "there were few significant differences among treatments in mean scores lof measures of depressive symptoms and improvement in functioning] . . at termination of treatment. The few differences ... favored IMI-CM, compared with PLA-CM. IMI-CM also had a more rapid effect (Watkins et al., 1993) ... [Though] there were virtually no significant differences among the three active treatments ... there was a consistent ordering of treatments at termination, with IMI-CM generally doing best, PLA-CM worst, and the two psychotherapies in between but generally closer to IMI-CM."

Elkin (1994) also summarized "secondary" (p. 94) analyses in which patients were dichotomized into more and less severely depressed based on their initial scores on the HSRD ( 20 or greater to reflect more severe depressive symptomatology) or into more and less severely impaired on the initial GAS (50 or less to reflect more severe symptomatology and impairment of functioning). "These analyses revealed a number of significant Treatment $\times$ Severity interactions, especially for the GAS dichotomy ... There were no significant differences among any of the treatment groups, including PLA-CM, for the less severely depressed patients according to either severity criterion. Significant differences were found only for the more severe subsamples, for whom there was some evidence of the effectiveness of interpersonal therapy [compared with PLA-CM] with these patients and strong evidence of the effectiveness of imipramine plus clinical management" (Elkin et al., 1989, p. 971). Elkin et al. (1996, p.94) also reported on findings using random regression models (RRM; Elkin et al., 1995) to evaluate at termination "the interaction of treatment, time, and severity (as measured, alternatively, by continuous scores on the HRSD, the GAS, or the Beck Depression Inventory) . . Significant Treatment $\times$ Severity $\times$ Time interactions were found for all three of the severity measures. Post hoc analyses between pairs of treatment revealed that IMI-CM was significantly superior to all of the other treatments in reducing depressive symptoms (on the HRSD and the BDI) for those patients who were severely depressed and functionally impaired on the GAS. Both IMICM and IPT were either significantly or nearly significantly superior to CBT and PLA-CM for those patients who were severely depressed on the HRSD or the BDI." Elkin et al. (1996, p. 95) concluded that "IMI-CM ... was a very effective treatment in the TDCRP, especially for the more severely depressed and functionally impaired patients . . . [This] superiority of IMI-CM, in comparison with all of the other treatments for the more severely depressed and functionally impaired patients was, in part, due to its more rapid effects."

Despite the conclusion by Elkin et al. (e.g., 1996, p. 95) that IPT, as well as IMICM, had a significantly higher recovery rate at termination (6 or less on the HRSD) for more severely depressed and functionally impaired patients than did PI.A-CM, a number of other investigators (e.g., Klein \& Ross, 1993; Klerman, 1990) concluded that IMI-CM was the most effective treatment in the TDCRP. Klerman $(1990$, p. 687), for example, stated that IMI-CM "came out as the most effective of the treatments ... land] for the advocates of psychotherapy for depression, results of this study are disappointing." This conclusion that IMI-CM was the most effective treatment in the 
TDCRP seems premature for several reasons: (1) the relative effectiveness of IMI-CM occurred primarily around midrreatment, but this difference in symptom reduction among the three active treatment groups was not sustained at termination (e.g., Watkins et al., 1993); (2) the comparisons of therapeutic gain (e.g., Elkin et al., 1985, 1989; Klein \& Ross, 1993; Watkins et al, 1993) did not include evaluations of a series of ratings made by therapists, independent clinical evaluators (CEs), and patients at termination; and (3) the comparison of treatment groups was based on assessments conducted only during treatment and at termination, even though extensive followup assessments had been conducted at 6,12 , and 18 months after termination.

Only one report thus far has assessed treatment effects at follow-up (Shea et al., 1992), and these analyses were limited to dichotomous diagnostic criteria of recovery and relapse. Dichotomous criteria of recovery and relapse have several limitations: (1) they restrict the evaluation of finer distinctions such as degrees of symptomatic, functional, and phenomenological change; (2) they require a substantially larger sample to achieve the statistical power available with continuous variables; and (3) threshold values for defining recovery and relapse are somewhat arbitrarychanges in these thresholds could result in different patterns of recovery and relapse. In addition, shea et al. (1992) viewed patients' seeking further treatment as an indication of relapse. ${ }^{1}$

Analyses based on these dichotomous criteria of recovery and relapse indicated that approximately $21 \%$ of patients who started treatment in one of the three active treatments were considered to be "fully recovered" at termination (HRSD $<0$ ) and without relapse during follow-up (i.e., not meeting research diagnostic criteria [RDC] for major depressive disorder [MDD] for two consecutive weeks; shea, et al, 1992). Based on these findings, Elkin (1994, p. 131) notes, "What is the most striking in the follow-up data is the relative small percentage of patients who remain in treatment, fully recover, and remain completely well throughout the 18 month follow-up period" and though "these treatments are helpful to many patients serious consideration must be given to their limitations." Given the conclusion that the short-term treatments in the TDCRP were "insufficient for most patients to achieve full recovery and lasting remission" (Shea et al, 1992, p. 782; see also Elkin, 1994), seeking further treatment may indicate awareness in some patients of the insufficiency of the treatment they received. Thus, seeking additional treatment could be a constructive atrempt to deal with problems not fully addressed in the brief treatment provided.

Despite the limitations imposed by their use of dichotomous criteria of recovery and relapse to assess therapeutic gain, Shea et al. (1992, p. 782) found substantial differences at follow-up among treatment conditions. Although statistical tests wete not conducted on these treatment differences, patients in MM-CM had a lower rate of recovery, higher rate of relapse, and fewer symptom-free weeks than patients in the two psychotherapy conditions. Additionally, the percent of patients defined as "fully recovered" among the total sample who began treatment was higher in the two psychotherapy conditions (24\% in CBT and $23 \%$ in IPT) than in the two medication conditions (16\% in both IMI \& PLA), suggesting better outcome at follow-up in both psychotherapy conditions (Shea et al., 1992). Though one needs to be cautious about the stability of these findings because of somewhat arbitrary threshold values for

\footnotetext{
${ }^{1}$ Among recovered parients, three in CBT sought further treatment, as compared to eight in IPT, eight in IMI, and fout in PLA. As reported by Shea et al. (1992), recovered patients in IMI-CM who solight further treatment during the follow-up period, stayed in treatment for a substantially longer time (20.3 weeks on average) than patients in CBT (4.2 weeks), IPT (11.0 weeks), and PLA-CM ( 7.8 weeks).
} 
dichotomous criteria, these findings at follow-up are consistent with other studies that indicate better outcome in psychotherapy as compared to antidepressant medication (Blackburn, Eunson, \& Bishop, 1986; Evans et al,, 1992; Hersen, Bellack, Himmelhoch, \& Thase, 1984; Hollon, Shelton, \& Loosen, 1991; Kovacs, Rush, Beck, \& Hollon, 1981; McLean \& Hakstian, 1990; Miller, Norman, Keitner, Bishop, \& Dow, 1989; Rush, Beck, Kovacs, \& Hollon, 1977; Simons, Murphy, Levine, \& Wetzel, 1986; Wexler \& Cicchetti, 1992; Weissman, Klerman, Prusoff, Sholomskas, \& Padian, 1981). These findings are also consistent with the conclusion of Antonuccio and colleagues (Antonuccio, Danton \& DeNelsky, 1995; Antonuccio, Danton, DeNelsky, Greenberg \& Gordon, 1999; Antonuccio, Thomas \& Danton, 1997, p. 187) that a "comprehensive review of the existing evidence suggests that psychotherapy . . . is at least as effective as medication in the treatment of depression, even if severe . . for both vegetative and social adjustment symptoms, especially when patient-related measures are used and long-term follow-up is considered."

Given these considerations, it seems premature to draw conclusions about the relative efficacy of IMI-CM in the TDCRP (e.g., Elkin, 1994; Klein \& Ross, 1993; Klerman, 1990) until a comprehensive assessment is conducted, both at termination and follow-up, on the broad spectrum of measures available in the TDCRP. This comprehensive assessment should include evaluations of symptoms, functional capacities, and reports by patients about their satisfaction with the treatment they received and its impact on their lives, particularly after a substantial period following termination. Such analyses might answer "one of the most important questions in studying the effectiveness of psychotherapies in the treatment of depression... whether they have long-term or prophylactic effects as compared to anti-depressant drugs, particularly whether, by providing patients with coping skills, they can help to prevent or delay relapse" (Elkin, 1994, p. 131).

The present analyses further examined treatment differences in the TDCRP, using the broad range of measures that had been obtained at termination and follow-up, including the four primary symptom measures (HRSD, GAS, HSCI-90, and BDT) and the Social Adjustment Scale (SAS); as well as ratings by therapists, independent CEs, and patients, especially patients' ratings at follow-up of their ability to "develop more adaptive coping mechanisms and ... to deal more effectively with their lives and the symptoms of depression" (Shea et al, 1992, p. 783). In evaluating the broad range of measures at termination and follow-up, we thought it important to control for pretreatment characteristics of patients that prior research indicated significantly influenced outcome. Additional analyses of data from the TDCRP (Blatt, Quinlan, Pilkonis, \& Shea, 1995; Blatt, Zuroff, Bondi, Sanislow, \& Pilkonis, 1998; Blatt, Zuroff, Quinlan, \& Pilkonis, 1996) revealed that pretreatment Perfectionism (PFT) or selfcriticism, as measured by one of the two factors of the Dysfunctional Attitudes Scale (DAS; Weissman \& Beck, 1978), independent of treatment condition, significantly impeded outcome at termination, as assessed by residualized gain scores of each of the five primary symptom measures as well as by a composite score based on these five measures. Also, better outcome was found in patients in a long-standing relationship or married (e.g., Elkin, 1994; Elkin et al., 1985) and in some analyses severity was found to interact with treatment in predicting outcome (Elkin et al., 1989). ${ }^{2}$

${ }^{2}$ Using point-biserial correlations, pretreatment perfectionism was not significantly correlated with di chotomous estimates of severity (HRSD $=-.01$; GAS - 04) but was significantly correlated with marital status-perfectionist patients were significantly less likely to be married $(r--21, p<.01)$. The two dichotomous severity variables (HRSD and GAS) were not significantly related to marital status. 
The substantial contribution of pretreatment PFT, matital status, and initial severity to outcome may obscure differences among the treatments. Thus, analyses in this paper extend prior evaluations of treatment effects in the TDCRP in two ways: (1) by comparing the full range of measures of therapeutic gain gathered at termination and follow-up, and (2) controlling for extratreatment variables that had a demonstrated effect on outcome.

\section{METHOD}

\section{SUBJECTS}

Two hundred fifty patients had been randomly assigned to 4 treatment conditions across three sites; 239 patients began treatment and 162 patients were defined as treatment completers, having participated in at least 12 treatment sessions over at least 15 weeks. These nonbipolar, nonpsychotic outpatients met well-specified criteria for MDD, including research diagnostic criteria for a current episode of definite MDD (Spitzer, Endicott, \& Robins, 1978) that had been present for at least the previous two weeks, and a score of 14 or more on an augmented 20 -item version of the 17-item HRSD. Among the patients who began treatment, 70\% were female, 38\% were definite endogenous by RDC criteria, and $64 \%$ had had one or more prior episodes of major depression. The average age was 35 . Inclusion and exclusion criteria and sample characteristics have been described in previous publications (Elkin et al., 1985; Elkin et al., 1989; Imber et al., 1990; Sotsky et al., 1991; Watkins et al., 1993).

\section{TREATMENT CONDITIONS AND ASSESSMENTS OF THERAPEUTIC GAIN}

The treatment conditions and the interview and self-report assessments of overall dinical functioning (GAS and HSCL-90) and symptoms of depression (HRSD and BDD), as well as social adjustment (SAS), have been described in detail earlier (Elkin et al., 1989; Imber et al., 1990; Sotsky et al., 1991). ${ }^{3}$ In addition to these five symptom measures, ratings were obtained from therapists and CEs about patients' progress at varjous points during treatment and termination; patients also rated their progress at termination. At follow-up, patients and CEs also rated patients' current level of functioning and extent of therapeutic gain (therapists did not participate in the follow-up).

Chinical evaluators (CEs) conducted Schedule for Affective Disorders and Schizophrenia-Change Version (SADS-C) interviews during treatment, at termination, and at the follow-up evaluations. They also used seven-point Likert scales at termination and follow-up to rate patients' level of depression, general clinical functioning, social adjustment, and the overall success of treatment, including the extent of the patient's improvement. CEs also indicated (Yes/No) at termination whether the patient seemed satisfied with treatment and, at termination and follow-up, whether the patient needed further treatment.

Patients, using seven-point Likert scales at termination and follow-up, rated their satisfaction with treatment, current clinical condition, and the extent of change since

${ }^{3}$ Ratings of marital and family functioning were onitred from our scoring of the SAS because treatment conditions differed significantiy in the proportion of married subjects. 
beginning and since completing treatment. At follow-up, patients using seven-point Likert scales also rated how much treatment helped in specific areas of their life adjustment: interpersonal relationships, recognizing symptoms of depression, controlling self-critical thoughts, coping with depressive symptoms, changing depressive attitudes, and the extent to which treatment facilitated understanding how depression was related to rigid attitudes, difficulty with close relationships, and possibly had both biological and emotional causes.

Therapists, using seven-point Likert scales at termination, rated patients' current level of functioning and degree of clinical change; severity of depression; functioning in work, sexual adjustment, and in social, marital, and parental roles; and their capacity to cope with personal problems. Therapists also rated how much they liked the patient and indicated (Yes/No) whether they thought the patient was satisfied with treatment, whether the patient needed further treatment, as well as their own satisfaction with the treatment they had provided. Primary analyses in this paper are based on patients who completed treatment $(n=162)$, but additional analyses were conducted on the "end-point" sample $(n=204)$ that included all patients who had at least four treatment sessions but who dropped out of treatment or had been withdrawn from treatment for clinical reasons.

\section{DATA REDUCTION}

Prior analyses (Blatt et al., 1996) revealed that residualized gain scores of the five primary symptom measures in the TDCRP (HRSD, BDI, GAS, HSCL-90, and SAS) form one primary factor at termination; all five residualized scores loaded substantially $(>.79)$ on one factor with an eigenvalue of 3.78 , accounting for $75.6 \%$ of the variance. Because these measures shared much of their variance, they were combined to create an aggregate measure of maladjustment at each evaluation point (Blatt et al., 1998). We calculated $z$-scores for each of the five variables, using the pooled mean and the pooled within-time period standard deviation over five observation points (at pretreatment and at 4, 8,12, and 16 weeks of rreatment). An aggregate maladjustment score (AMS) was computed for each observation point, including follow-up, by taking the mean of the five $z$-scores at that point. Cronbach alphas for the resulting aggregates throughout the treatment and follow-up ranged from .88 to 94 , except for the pretreatment assessment $(\alpha=.69)$ which is probably suppressed because of a restricted range due to fixed selection criteria.

Because therapists and patients made extensive ratings at several assessment points, these ratings were consolidated through principal-components factor analysis using varimax rotation and the scree test. Factor analysis was conducted on the 12 items rated by the therapists at termination about patients' current level of functioning and degree of therapeutic gain. Excluded from this factor analysis, however, were two items concerning marital and parental adjustment, because including these two items would have required eliminating from this factor analysis the approximately one third of the sample who were not martied. These two marital/patental items were evaluated separately. Factor analysis indicated that the 12 items form two primary factors. The first factor, labelled degree of clinical change, had an eigenvalue of 4.33 with factor loadings greater than .68 for change in clinical condition, work functioning, capacity to handle problems, social functioning, and depressive symptoms, as well as current clinical condition and severity of depressive symptoms. The second factor, labelled current level of functioning, had an eigenvalue of 3.61 and factor loadings greater than .68 for current social, work, and sexual adjustment and 
functioning, and current ability to handle personal problems, as well as change in sexual adjustment.

Factor analysis of patient ratings at the 18-month follow-up yielded two primary factors. Factor I, labelled life adjustment, had an eigenvalue of 5.18 and factor loadings greater than .70 for the eight items that assessed the degree to which patients thought treatment helped them to have satisfying relationships with others, recognize symptoms of depression, develop better skills for dealing with problems in interpersonal relationships, keep negative thoughts from causing depression, cope with symptoms of depression, change attitudes associated with depression, and understand both how their depression results from their rigid attitudes about self and how their depression was related to their difficulties in relationships. Factor II, labelled current clinical condition, had an eigenvalue of 3.52 and factor loadings greater than .88 for three ratings: current condition, degree of change since beginning treatment, and degree of change since completing treatment. Two additional items assessing overall satisfaction with treatment and the degree to which the patients viewed depression as having biological/physical as well as emotional causes, did not load substantially on either of these two primary factors. These two items were treated as separate variables.

Because CEs rated only five items at both termination and at follow-up, these items were treated as separate variables. We focused our analyses on the 18-month follow-up evaluation because different patients, to some degree, participated in the three follow-up assessments at 6,12, and 18 months.

\section{DATA ANALYSES}

Dependent variables (AMS, and ratings by therapists, CEs, and patients at termination and follow-up) were subjected to hierarchical multiple regression analyses (Cohen \& Cohen, 1983) with variables entered in the following order: initial severity, currently in a stable relationship, ever married, PFT, Treatment, and the Treatment $\times$ Initial Severity product term. These analyses are equivalent to those conducted by Klein and Ross (1993), except that PFT was also included as a covariate. In analyses of the AMS at termination and 18-month follow-up, the pretreatment aggregate of the five primaty symptom measures was used as the estimate of severity. In analyses of various ratings by therapists, CEs, and patients at termination and follow-up, initial severity was defined, as in Klein \& Ross (1993), by pretreatment HRSD Or GAS.

\section{RESULTS}

\section{THERAPEUTIC GAIN AT TERMINATION}

Table 1 summarizes the hierarchical multiple regression analyses conducted on outcome measures at termination. Table 2 presents means for the four treatment groups, as well as means adjusted for group differences in the covariates-for those pretreatment patient variables with significant $(p<.05)$ treatment effects. As indicated in Table 1, initial severity (as measured by the pretreatment AMS), marital status, and pretreatment PFT were all significant predictors of the AMS at termination; the Treatment main effect and the Treatment $\times$ Severity interaction, however, were not significant. This analysis was repeated for each of the five measures in the AMS 


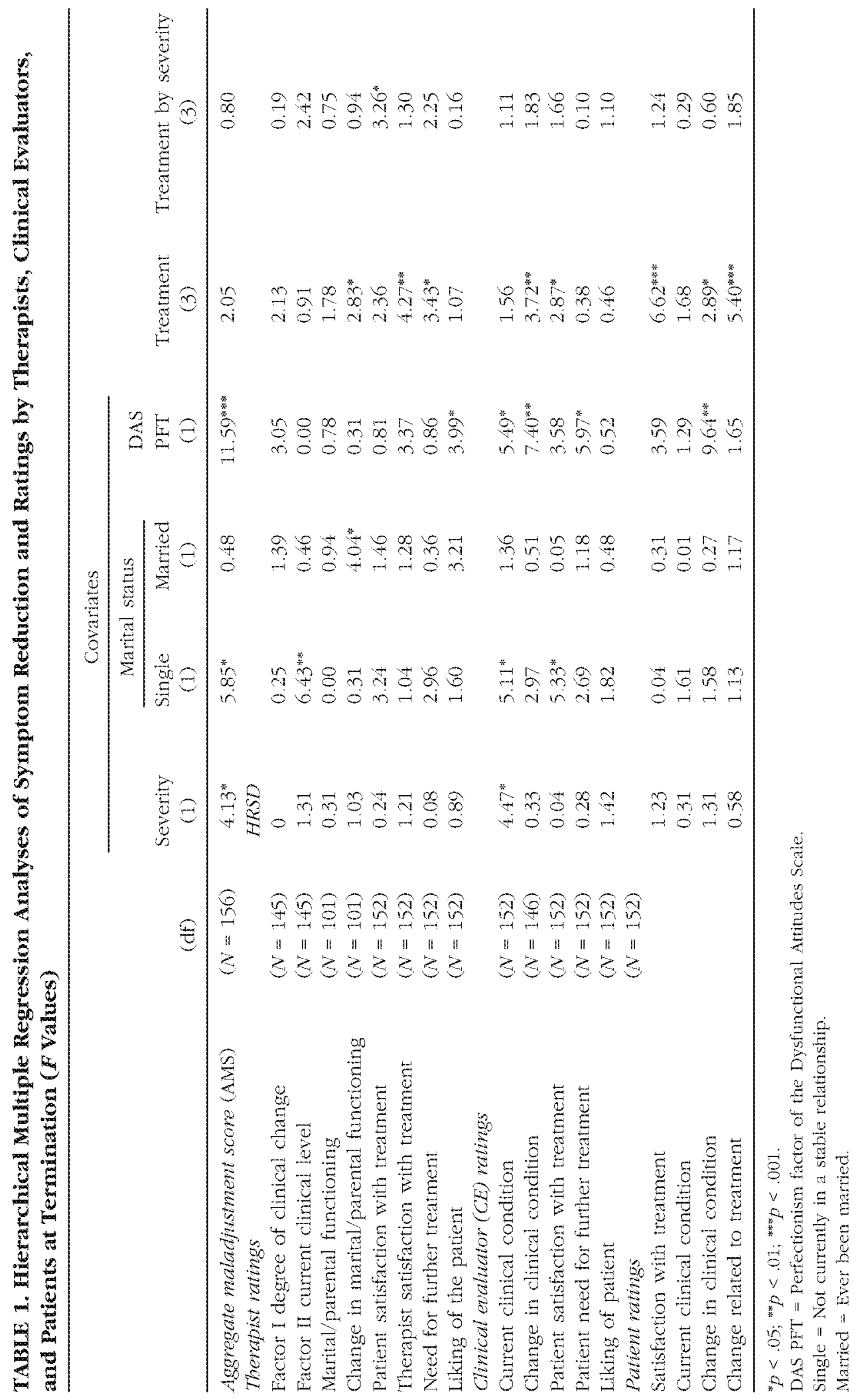




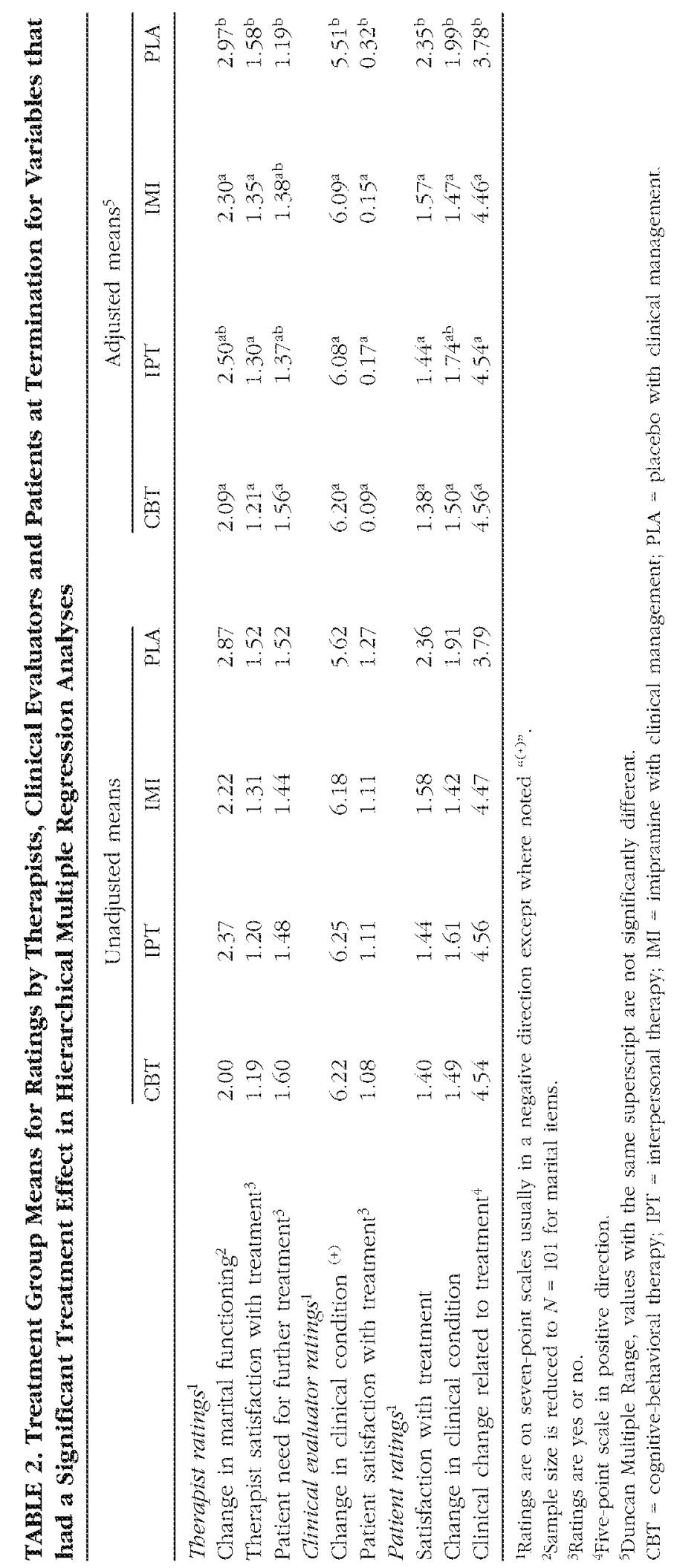


(HRSD, BDI, GAS, HSCL-90, and SAS). Severity was a significant predictor for all measures at termination (except GAS), as were marital status and pretreatment PFT. None of the Treatment $\times$ Severity interactions were significant. ${ }^{4}$ A significant $(p<$ .05) treatment difference, however, was found for the HSCL-90; the Duncan Multiple Range Test indicated significantly less symptom reduction on the HSCL-90 in PLACM than IMI-CM and IPT.

In addition to these measures of clinical symptoms, ratings were obtained at termination from therapists, CEs, and patients. As indicated in Table 1, severity (as measured by pretreatment HRSD) was rarely a significant predictor of these ratings. In addition, only one Treatment $\times$ Severity interaction reached statistical significancewhether therapists thought patients were satisfied with treatment. Given that only one of the Severity $\times$ Treatment interactions reached statistical significance, we thought it appropriate to examine the main effects of treatment. A summary of regression analyses of ratings at termination by therapists, CEs, and patients in the four treatment conditions, controlling for the pretreatment predictors of treatment outcome, is presented in Table 1, using the HRSD as the measure of initial level of severity. Similar results were obtained using GAS as the measure of initial severity. A presentation of these results with the GAS is available from the authors. Table 2 presents means at termination for the four treatment groups, as well as means adjusted for group differences on the covariates (severity, marital status, and PFT) for the pretreatment patient variables on which there were signifjcant treatment effects.

In ratings by therapists at termination, significant treatment effects were found at termination in change in marital/parental functioning, therapist's satisfaction with treatment, and whether the therapist thought the patient needed additional treatment. As presented in Table 2, the Duncan Multiple Range indicated that in all three of these significant treatment effects, differences were between lower ratings therapists gave to patients in PLA-CM and ratings made by the therapists in one or more of the three active treatments. Significant treatment differences were also found among ratings by CEs of change in clinical condition and whether CEs thought the patient was satisfied with treatment. The primary difference in these ratings was again berween PLA$\mathrm{CM}$ and the three active treatments. The same pattern was observed in ratings by patients at termination. Patients in PLA-CM were significantly less satisfied with treatment, thought they had changed less, and that their clinical change was less related to the treatment they received than patients in the three active treatments.

In summary, ratings at termination by therapists, CEs, and patients, as well as scores on the five symptom measures, indicated that outcome among the three active treatments was not significantly different, but that the active treatments usually resulted in significantly more therapeutic gain and greater satisfaction with treatment than did placebo. These findings are consistent with earlier analyses of treatment effects reported by Watkins et al. (1993), using only the HRSD and GAS as outcome measures. What treatment differences did exist at termination, both in symptom reduction and ratings by therapists, CEs, and patients, were primarily between PLACM and one or more of the three active treatments, especially IMI-CM.

In evaluating these differences between the three active treatments and the placebo group at temination, especially between the active and inactive medication groups, it is important to note that therapists in the double-blind medication condi-

${ }^{4}$ The Treatinent $\times$ Severity interaction for the BDI approached $(p<.10)$ significance. Klein and Ross (1993) reported trends $(p<10)$ for severity interactions for both the BDI and the IRSD. Controlling for PFT, however, reduced the significance of the Treatment $\times$ severity interaction for the HRSD to $p<.30$ 
tion had been asked to judge at midtreatment, at the end of the eighth treatment session, whether the patient was receiving an active or inactive medication, and the therapists were able to make this differentiation. with considerable accuracy (79\%). Also by the eighth session, $55 \%$ of the patients in the two medication conditions (IMI and PLA) had spontaneously indicated to their therapist that they thought they knew whether they were receiving an active or an inactive medication, and $75 \%$ of those patients correctly identified their treatment condition.

\section{THERAPEUTIC GAIN AT 18-MONTH FOLLOW-UP}

Table 3 presents hierarchical multiple regression analyses comparing the AMS at the 18-month follow-up in the four treatments, controlling for pretreatment severity, marital status, and PFT. To maintain comparability of the sample to that used in the intake-termination analyses, these analyses were restricted to patients for whom termination data were available. As indicated in Table 3 , no significant differences were found at the 18-month follow-up among the four treatment conditions in symptom reduction as measured by the AMS. For each of the five variables that entered into this aggregate score, only one of the interactions was significant $(p<.01)$ : the interaction of treatment and severity on the HSCL-90. Outcome was better $(p<.05)$ among less-disturbed patients who had been in CBT than in PLA-CM. Given that only one interaction was significant and not readily interpretable, we compared treatments at follow-up by examining the main effect of treatment. No significant differences were found among the four treatments on any of the five measures that comprise the AMS.

Controlling for initial severity prior to the start of treatment assesses the net effect of the entire treatment process at the 18-month follow-up. To assess postherapy change, we also conducted these analyses controlling for level of severity at termination (at 16 weeks). This enabled us to assess the degree to which treatment effects at termination were consolidated at follow-up. In terms of the AMS, no significant Treatment $\times$ Severity interaction or significant treatment main effect was found at the 18-month follow-up. The only significant predictor of level of the AMS at 18 months was the AMS at termination $(F=29.08, p<.0001)$.

Table 3 also presents hierarchical multiple regression analyses for ratings made by patients and CEs at the 18-month follow-up. Table 4 presents mean scores for those ratings with significant differences among the four treatment groups, as well as the means adjusted for group differences in the covariates (severity, marital status, and PFT). Severity (defined by HRSD or GAS) was a significant predictor of patient ratings of their ability to recognize their symptoms of depression, the degree of their satisfaction with treatment, and whether they thought their depression had biological/physical as well as emotional causes. Because only one of the Treatment $\times$ Severity interactions was significant (parients' ratings of degree of change since termination of treatment $[p<.043]$, pretreatment severity as measured by the GAS), we evaluated treatment main effects at the 18-month follow-up.

As in the analysis of data at termination, Table 3 presents analyses at the 18 month follow-up using HRSD as the measure of initial severity. No significant differences were found among the four treatment conditions in the ratings made by the CEs. CEs did not perceive any significant differences in current clinical condition or clinical change at the 18-month follow-up among patients in the four treatment groups. The results using GAS as the measure of initial severity are comparable, and a presentation of these results is available from the authors. Analysis of patient ratings at the 18-month follow-up also indicated no significant differences among patients in 


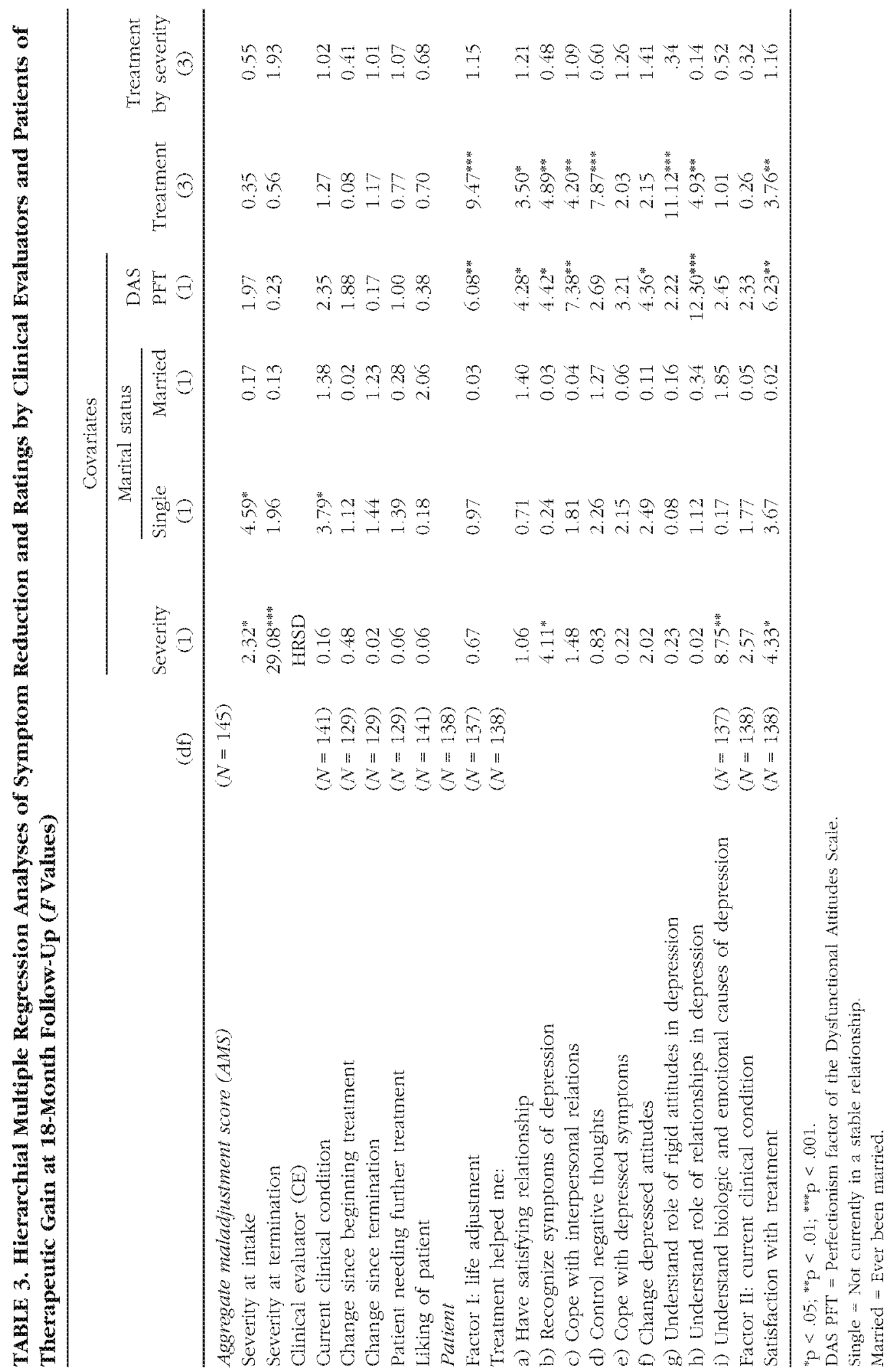




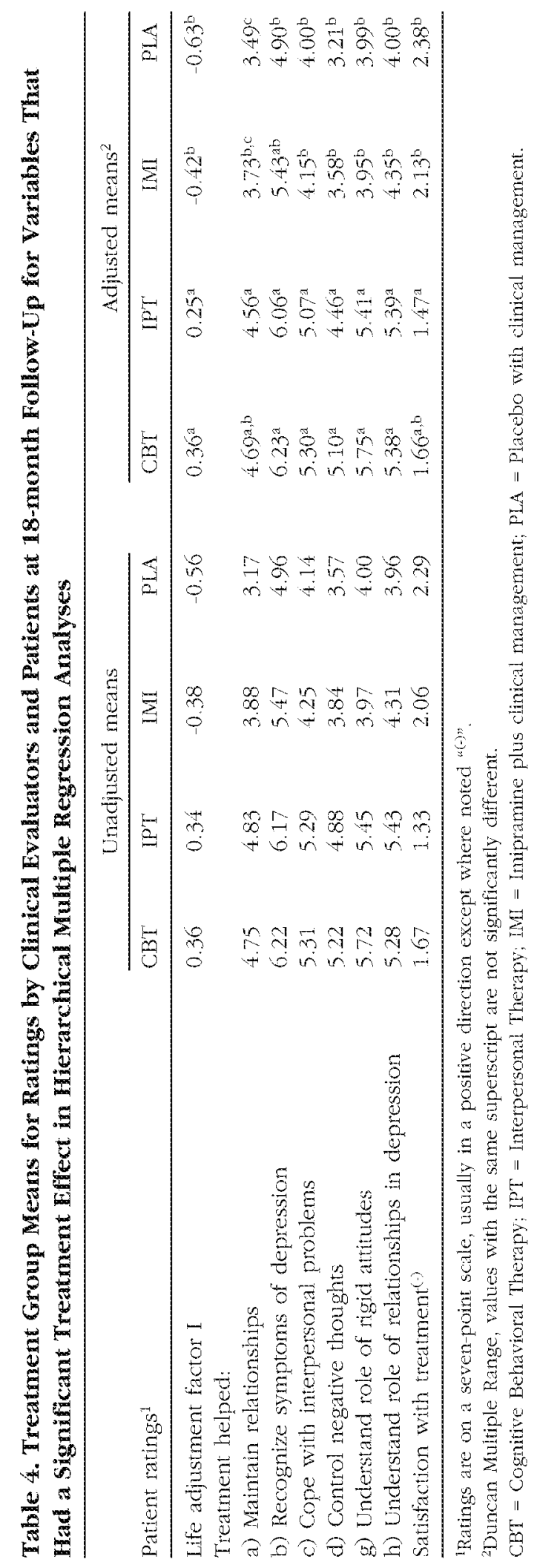


the four treatment groups in their ratings of their overall current condition (Factor ID) or in the three items that entered into this factor (current clinical condition and degree to which patients thought they had improved since beginning and since terminating treatment).

Significant treatment differences, however, did emerge in patient ratings of their degree of satisfaction with their treatment and the impact that treatment had on their life adjustment. As indicated in Tables 3 and 4, patients in IPT reported significantly greater satisfaction with treatment than patients in IMI-CM and PLA-CM, with patients in CBT falling between these two groups. Patients in both IPT and CBT reported significantly more positive effects on their life adjustment (Factor I) as a consequence of their treatment than did patients in the two medication conditions. These significant treatment effects emerged only in the last follow-up assessment. No significant treatment effects were found for degree of satisfaction with treatment or for the effects of treatment on life adjustment at the six-month follow-up. Significant treatment effects began to emerge only at the 12-month follow-up assessment, when patients in IPT reported significantly more satisfaction and greater effects on life adjustment than patients in IMI-CM, with patients in CBT and PLA-CM falling between these two groups. These treatment effects became even clearer at the last followup assessment, conducted 18 months after treatment had been terminated. A random regression analysis that included available data from all patients, regardless of how many weeks of treatment they bad completed, revealed a significant Treatment $\times$ Time interaction for the life adjustment factor. This factor increased significantly over the three follow-up assessments for the two psychotherapy conditions, while it decreased in the two medication conditions. Interestingly, it apparently takes considerable time for this consolidation of treatment effects to take place.

To explore further the significant difference among treatment groups on the life adjustment factor at the 18-month follow-up, we evaluated differences among treatment groups on each of the eight items included in this factor. Differences between patients in the two psychotherapy conditions (CBT and IPT), as compared to the two medication conditions (IMI-CM and PLA-CM), were significant on six of the eight items that entered into this overall rating, including the degree to which patients thought that treatment helped them have more satisfying interpersonal relationships $(p=.018)$, cope more effectively with interpersonal relationships $(p=.008)$, be better able to recognize their symptoms of depression $(p=.003)$, control negative selfcritical thoughts $(p<.001)$, and understand how rigid self-attitudes $(p<.001)$ and distuptions in interpersonal relationships $(p=.002)$ contributed to their depression. The four treatment groups did not differ, however, in the degree to which they thought that both biological and emotional factors might have contributed to their depression. Thus, while no significant differences existed among treatment groups in measures of symptom reduction and ratings of general clinical condition at the 18-month follow-up, both CBT and IPT, as compared to the medication conditions, appeared to more fully "help patients develop more adaptive coping mechanisms and enable them to deal more effectively with their lives and with the symptoms of depression" (Shea et al., 1992, p. 783; see also Elkin, 1994, p. 131).

We explored the possibility that these significant treatment differences in reports of satisfaction and greater effects on life adjustment might be a consequence of differences in expectations that patients had when they began treatment. Patients at intake rated, on seven-point Likert scales, things they thought "would be most helpful . . . in treating [their] depression." We differentiated the use of medication from the other items which seemed directed toward some form of psychotherapeutic in- 
tervention. None of the correlations of these two sets of items with the 18-month follow-up ratings made by patients of their current clinical condition (Factor II), their degree of satisfaction with treatment, and the degree to which they thought treatment had affected their life adjustment (Factor 1 ), reached statistical significance for the total sample or for the two psychotherapy conditions or the two medication conditions considered separately. Thus, the significantly greater satisfaction and degree of impact on life adjustment reported by patients in the psychotherapy conditions, as compared to the medication conditions, did not appear to be a consequence of differences in patients' pretreatment expectations about the nature of treatment they would receive for their depression.

The analyses presented thus far are based on treatment completers who participated in 12 or more treatment sessions over at least 15 weeks. One potential criticism of studying treatment completers is the possibility that patients may be differentially responsive to the various treatments, thereby biasing the selection of patients who remained in treatment in each of the treatment groups (Elkin, 1994, p. 135; Klein \& Ross, 1993; Shea et al, 1992). To address this potential confound, additional analyses were conducted, including the 24 patients who had participated in the follow-up evaluation at 18 months who were in the end-point sample-patients who had at least four treatment sessions but who had either dropped out of treatment or were withdrawn for clinical reasons. Results with this extended end-point sample are similar to the findings with only treatment completers, with two exceptions: (1) significant differences are now obtained between the two psychotherapy and the two medication conditions on all eight items contained in the life adjustment factor at the 18 month follow-up, and (2) now a significant $(p<.001$ ) Severity (defined by GAS) $\times$ Treatment interaction indicates greater satisfaction with treatment in IPT than IMICM for less severely impaired patients. This same pattern was observed among more severely impaired patients in the end-point sample, but this difference between IMI$\mathrm{CM}$ and the two psychotherapy conditions did not reach statistical significance.

\section{DISCUSSION}

Analyses of the various measures of therapeutic gain during treatment, at termination, and at 18-month follow-up in the TDCRP indicate that medication (IMI-CM) results in a significant reduction in symptoms at midtreatment (eighth week) in comparison to CBT and IPT, as well as placebo (e.g., Elkin et al, 1996; Klein \& Ross, 1993), but this relative advantage for medication is markedly diminished at termination (e.g., Shea et al, 1992; Watkins et al., 1993). The significantly greater reduction of symptoms at midtreament in the active medication condition (IMI-CM) has led a number of investigators (e.g., Elkin et al., 1985, 1989, 1995, 1996; Klein \& Ross, 1993; Kleman, 1990) to conclude that medication (i.e., imipramine) was more effective than cognitive-behavioral therapy (CBT) and double-blind placebo (PLA-CM), and somewhat more effective than interpersonal therapy (IPT), in the brief outpatient treatment of major depression, especially for more severely depressed patients. Despite this rapid reduction of symptoms in IMI-CM at midtreatment, however, the three active treatments were not significantly different at termination in degree of symptom reduction (Shea et al, 1992; Watkins, Leber, Imber, \& Collins, 1986). Analyses of ratings by therapists, CEs, and patients at termination are consistent with these findings based on symptom measures that the three active treatments were not significantly different at termination. 
Analyses of data obtained 18 months after termination of treatment are consis-tent with findings at termination indicating a lack of significant differences among the four treatment conditions in symptom reduction, as measured by the five primary measures (HRSD, BDI, GAS, HSCL-90, and SAS). Also, no significant treatment effects were found in the 18-month follow-up ratings by patients and CES of the patients' level of clinical functioning. But patients at the 18-month follow-up had also rated a series of questions about the effects of treatment on various aspects of their life adjustment (these ratings had not been obtained at termination). Patients in IPT reported significantly greater ovetall satisfaction with treatment, and patients in both IPT and CBT reported significantly more constructive effects on life adjustment than patients in the two medication conditions. Patients in the two psychotherapy conditions thought that their treatment had significantly greater effect on helping them to establish better interpersonal relationships, to cope with those relationships more effectively, and to recognize more fully their symptoms of depression than patients in IMI-CM and PLA-CM. Patients in both IPT and CBT, as compared to the two medication conditions, also thought that their treatment had helped them control more successfully their negative self-critical thoughts and to understand more fully how their rigid self-attitudes and disruptive interpersonal relationships contributed to their depression.

These positive reports at the 18-month follow-up by patients in the two psychotherapy conditions, as compared to the medication conditions, are open to a variety of interpretations, including the possibility that they are the consequence of cognitive dissonance because of the greater effort involved in psychotherapy than in medication or because indoctrination in psychotherapy tends to encourage patients to respond in more socially desitable ways. Whatever mechanisms contributed to these significant treatment differences 18 months after termination, patients in the two psychotherapy conditions reported feeling in fuller control of important aspects of their lives, and that their treatment enabled them to develop more adaptive coping mechanisms and to deal more effectively with their experiences of depression. These findings are consistent with the results of the follow-up report by shea et al. (1992) of a tendency toward a higher rate of recovery, more symptom-free weeks in follow-up, and less relapse among recovered patients in the two psychotherapy groups than in the IMI-CM group. These findings extend and elaborate the suggestion by Elkin (1994, p. 131) of "some hint in the follow-up data that the psychotherapies might do a bit better in the long-term" (see also shea et al., 1992, p. 786).

The more constructive effect on life adjustment in the two psychotherapy groups, as compared to the two medication groups, is also consistent with the recent report by Segal, Gemar, and Williams (1999) that patients who recovered from major depression through CBT, as compared to patients who recovered through pharmacotherapy, had a significant decrease in dysfunctional attitudes when these attitudes were assessed under induced negative mood. Segal et al found that patients' reactions to this mood induction procedure, independent of the treatment therapy received, was predictive of depressive relapse several years later. Similar findings have been reported by Strauman et al. (2000) that depressed patients seen in CBT or IPT, as compared to pharmacotherapy, had significant reduction in posttreatment negative self-evaluation, both conscious and automatic. Strauman et al. (2000) suggested that their findings indicate that psychotherapy (CBT or IPT) is more effective than medication in reducing reactivity to dysphoric stimulation in previously depressed patients and thus their vuinerability to relapse. 
In contrast to the lack of differences among the three active treatment groups in the TDCRP in symptom reduction at termination and at the 18-month follow-up, consistent and significant differences among treatment groups in the effects of treatment on life adjustment at follow-up raise questions about an exclusive focus on symptom reduction to evaluate therapeutic gain. Differences among patients in their reports of the effects of treatment on their life adjustment suggest the importance of evaluating broader life functioning and the meaning and value that treatment has for the patient in a variety of areas (Blatt, 1995). These more broadly based assessments also hold the promise of possibly identifying some of the mechanisms that could delay or prevent relapse. These findings also suggest a possible sequence to therapeutic change. Symptom reduction may be an important first step in therapeutic change, but equally important may be the subsequent consolidation of feeling more able to cope with life situations and various potential depressogenic life stressors, thus forestalling the reoccurrence of clinical depression (see also Howard, Lueger, Maling, \& Martinovich, in press). Treatment should not only reduce symptoms but also the vulnerability to subsequent potentially disruptive experiences. Both of these dimensions need to be assessed when comparing the effects of different types of therapeutic intervention (Zuroff, Blatt, Sanislow, Bondi, \& Pilkonis, 1999).

\section{ACKNOWLEDGMENTS}

We express our appreciation to the investigators in the Treatment for Depression Collaborative Research Program (TDCRP) for providing access to their data set. The principal collaborators at the National Institute of Mental Health (NIMH) were Irene Elkin, Coordinator (now at the University of Chicago); M. Tracie Shea, Associate Coordinator (now at Brown University), John P. Docherty (now at New York Hospital); and Morris B. Parloff (now at Georgetown University). The principal investigators and project coordinators at the three participating research sites were as follows: Stuart M. Sotsky and David Glass, George Washington University; Stanley D. Imber and Paul A. Pilkonis, University of Pittsburgh; and John T. Watkins (now at the Center for Cognitive Therapy, Atlanta, Georgia) and William Leber, the University of Oklahoma. The principal investigators and project coordinators at the three sites responsible for training therapists were as follows: Myrna Weissman, Eve Chevron, and Bruce J. Rounsaville, Yale University (Myrna Weissman is now at Columbia University); Brian F. Shaw and T. Michael Vallis, Clarke Institute of Psychiatry; and Jan A. Fawcett and Phillip Epstein, Rush Presbyterian-St. Luke's Medical Center. Collaborators in the data management and data analysis aspects of the program were C. James Klett, Joseph F. Collins, and Roderic Gillis of the Veterans Affairs Cooperative Studies Program, Perry Point, Maryland.

The analyses presented in this article were conducted without support from or the endorsement of NIMH.

We are indebted to Paul A. Pilkonis for his comments and suggestions.

\section{REFERENCES}

Antonuccio, D. O., Danton, W. G., E DePelsky, G $Y$. (1995). Psychotherapy versus medication for depression: Challenging the conventional wis
Gom with data. Professonal Psychology: Research and Practice, 26, 574-585.

Antonucrio, D. O., Danton, W. G., DeNelsky, G. Y. 
Greenberg, R. R., \& Gordon, J. S. (1999). Rais ing questions about antidepressants. Psycbo therapy and Psychosomatics, 68, 3-14.

Antonuccio, D. O., Thomas, M., \& Danton, W. G (1997). A cost-effectiveness analysis of cognitive behavior therapy and Fluoxetine (Prozac) in the treatment of depression. Behavior Therapy, 28 , $187-210$

Beck, A. T., \& Beamesderfer, A. (1974). Assessment of depression: The Depression Inventory. In P. Pinchot (Ed.), Modem Problems of Pharmacopsychiatry: Psychologicat Measurements in Psychopharmacology (7th ed., pp. 151-169). Basel, switzeriand.

Beck, A. T., Ward, C. H., Mendelsohn, M., Mock, J., \& Erbaugh, J. (1960). An inventory for mea suring depression. Arcbives of General Psychia$t r y, 4,892-398$.

Blackburn, M., Eunson, K. M. \& Bishop, S. (1980). A two-year naturalistic follow-up of depressed patients treated with cognitive therapy, pharmacotherapy and a combination of both. Journal of Affective Disorders, 10, 67-75.

Bhatt, S. J. (1995). Why the gap between psycho therapy research and clinical practice: A response to Barry Woife. Joumal of Psychotberapy Integration, 5, 72-76.

Blatt, S. J., Quinian, D. M., Pilkonis, P. A., \& Shea, T. (1995). Impact of perfectionism and need for approval on the brief treatment of depression: The National Institute of Mental Health Treat ment of Depression Collaborative Research Pro gram revisited. Joumal of Consulting and Clinical Psychology, 63, 125-132.

Blatt, S. J., Zuroff, D. C., Bondi, C. M., Sanislow, C., \& Pilkonis, P. (1998). When and how perfectionism impedes the brief treatment of depression: Further analyses of the NIMH TDCRP. Joumal of Consulting and Clinical Psychology, $66,423-428$.

Blatt, S. J., Zuroff, D. C., Quinlan, D. M., \& Pikonis, P. A.(1996). Interpersonal factors in brief treatment of depression: Further analyses of the National Institute of Mental Health Treatment of Depression Collaborative Research Program. Joumal of Consulting and Clinical Psycbology, $64,162-171$

Cohen, J., \& Cohen, P. (1983). Applied multiple regression: Correlational analysis of the behav. ioral sciences. Hillsdale, NJ: Enlbaum.

Derogatis, L. R., Lipman, R. S., \& Covi, L. (1973). SCL-90; An outpatient psychiatric rating scale-preliminary report. Psychopharmacology Bulletin, 9, 13-28.

Elkin, 1. (1994). The NIMH Treatment of Depression Collaborative Research Program: Where we began and where we are now. in A. E. Bergin \& S. L. Garfield (Eds.), Handbook of psychotherapy ana behavior change (4th ed, pp. 114-135) New York: Wiley.
Elkin, I., Gibbons, R. D., Shea, M. T., \& Shaw B. F. (1996). Science is not a trial (but it can sometimes be a tribulation). Journal of Consulting and Clinical Psycbology, 64, 92-103.

Elkin, I., Gibbons, R. D., Shea, M. T., Sotsky, S. M., Watkins, J. T., Pilkonis, P. A., \& Hedeker, D. (1995). Initial severity and differential treatment outcome in the National Institute of Mental Health Treatment of Depression Collaborative Research Program. Joumal of Consulting and Clinical Psychology, 63, 841-848.

Elkin, I., Parlof, M. B., Hadley, S. W., \& Autry, J. H. (1985). NIMH Treatment of Depression Collaborative Research Program: Background and research plan. Archives of General Psycbiatry, 42, 305-316.

Elkin, I., Shea, M. T., Watkins, J. T., Imber, S. D. Sotsky, S. M., Collins, J. F., Glass, D. R., Pilkonis, P. A., Leber, W. R., Docheity, J. P., Fiester, S. J. \& Parloff, M. B. (1989). NiMH Treatment of Depression Collaborative Research Program: General effectiveness of treatments. Archives of General Psycbiatry, 46, 971-983.

Endicott, J., Spitzer, R. L., Fleiss, J. L., \& Cohen, J (1976). The Global Assessment Scale: A procedure for measuring overall severity of psychiatric disturbance. Archives of General Psychia$t r y, 33,766-771$.

Evans, M. D., Hollon, S. D., DeRubeis, R. J Piasecki, J. M., Grove, W. M., Garvey, M. J., \& Tuason, V. B. (1992). Differential relapse following cognitive therapy and phamacotherapy for depression. Archives of General Psychiatry, 49, $802-808$.

Hamilton, M. A. (1960). A rating scale for depression. Joumal of Neurology Neurosurgery PSychiatry, $6,56-62$

Hamilton, M. A. (1967). Development of a rating scale for primary depressive iliness. British journal of Social and Clinical Psychology, 6, 278296.

Hersen, M., Beliack, A. S., Himmeihoch, J. M., \& Thase, M. E. (1984). Effects of social skill train ing, amitriptyline, and psychotherapy in unipo lar depressed women. Bebavior Therapy, 15, $21-40$.

Hollon, S. D., Shelton, R. C., \& Loosen, P. T. (1991). Cognitive therapy and pharmacotherapy for depression. Journal of Consulting and Clinical Psychology, 59, 88-99.

Howard, K., Lueger, R., Maling, M., \& Martinovich, M. (in press). A phase model of psychotherapy change. Joumal of Consuling and Clinical Psycbology.

Imber, S. D., Pilkonis, P. A., Sotsky, S. M., Elkin, I., Watkins, J. T., Collins, J. F., Shea, M. T., Leber, W. R., \& Glass, D. R. (1990). Mode-specific ef fects among three treatments for depression. Joumal of Consuliting and Clinical Psychology, $58,352-359$. 
Klein, D. F., \& Ross, D. C. (1993). Reanalyses of the National Institute of Mental Health Trear ment of Depression Collaborative Research Program general effectiveness report. Neuropsychopharmacology, 8, 241-251

Klerman, G. L. (1990). Letter to the Editor. Ar chives of General Psychiatry, $47,686-688$.

Kovacs, M., Kush, A. J., Beck, A. T., \& Hollon, S. D. (1981). Depressed outpatients treated with cognitive therapy or pharmacotherapy: A oneyear follow-ip. Archives of General Psychiatsy, $38,33-39$

McClean, P. D., \& Hakstian, A. R. (1990). Relative endurance of unipolar depression treatment effects: Longitudinal follow-up. Toumal of Con sulting and Clinical Psycbalogy, 58, 482-488.

Miller, I. W, Norman, W. H. Keitnex, G. I. Bishop, 5. B., \& Dow, M. G. (1989). Cognitive-behavional treatment of depressed inpatients. Behavior Therapy, $20,25-47$.

Rush, A. J., Beck, A. T., Kovacs, M., \& Hollon, S. D. (1977). Comparative efficacy of cognitive therapy and phamacotherapy in the treatment of depressed outpatients. Cognitive Therapy and Research, 1, 17--37.

Segal, Z. V., Gemar, M., \& wiliams, S. (1999). Differential cognitive response to a mood challenge following successfil cognitive therapy or phamacotherapy for unipolar depression. Journal of Abnomal Psychology, $108,3-10$.

Shea, M. T., Elkin, I, Imber, S. D., Sotsky, S. M., Warkins, J. T., Collins, J. F., Pilkonis, P. A. Beckham, E., Glass, D. R., Dolan, R. T., \& Parloff, M. B. (1992). Course of depressive symptoms over follow-up: Findings from the National Institute of Mental Health Treatment of Depression Collaborative Research Program. Arcbives of General Psychiatry, 49, 782-787.

Simons, A. D., Murphy, G. E., Levine, J. L., \& Wetzel, R. D. (1986). Cognitive therapy and pharmacotherapy for depression: Sustained improvement over one year. Archives of General Psychiatry, $43,43-48$.

Sotsky, S. M., Glass, D. R., Shea, M. T., Pilkonis, P. A., Collins, J. F., Elkin, I, Watkins, J. T., Imber, S. D., Leber, W. R., Moyer I., \& Oliveri, M. E.
(1991). Patient predictors of response to psy chotherapy and pharmacotherapy: Findings in the NIMH Treatment of Depression Collaborative Research Program. American Journal of Psycbiatry, 148, 997-1008.

Spitzer, R. L., Endicott, J., \& Kobins, E. (1978). Research diagnostic criteria: Rationale and reliability. Archives of General Psychiatry, 35, 773-782. Strauman, T. J., Kolden, G. G., Stromquist, V. Davis, N., Kwapil, L., Heerey, E., \& Shneider, K. (2000). The effects of treatments for depression on perceived failure in self-regulation. Manuscript in review.

Watkins, J. T., Leber, W. R., Imber, S. D., \& Collins, J. F. (1986, May). NIMH Treatment of Depression Collabonative Research Programitemporal course of symptomatic change. Paper presented to Annual Meeting of the American Psychiatric Association, Washington, D.C.

Watkins, J. T., Leber, W. R., Imber, S. D., Collins, J. R., Eikin, I., Pilkonis, P. A., Sotsky, S. M., Shea M. T., \& Glass, D. R. (1993). NIMH Treatment of Depression Collaborative Research Program: Temporal course of change of depression. Joutnal of Consulting and Clinical Psycbology, 61. 858-864.

Weissman, A. N. \& Beck, A. T. (1978, August-September). Develoment and validation of ibe Dysfunctional Atitude Scale: A pretiminary investi gation. Paper presented at the meeting of the American Psychological Association, Toronto, Canjda.

Weissman, M. M., Klerman, G. L., Prusoff, B. A., Sholonskas, D. \& Padian, N. (1981). Depressed outpatients: Results one year after treatment with drugs and/or interpersonal psychotherapy. Arcbives of General Psycbiaim, 38, 51-55.

Wexler, B. E. \& Cicchetti, D. V. (1992). The outpatient treatment of depression: Implications of outcome research for clinical practice. Joumal of Newous and Mental Disease, 180, 277-286.

Zuroff, D. C., Blatt, S. J., Sanisiow, C. A., Bondi, C. M., \& Pilkonis, P. A. (1999). Vulnerability to depression: Reexamining stability and mood state dependence Joumal of Abnomal Psy chology, $108,76-89$

\section{Zusammenfasssung}

Frühere Analysen der Daten aus dem NIMH geförderten Forschungsprojekt zur Behandlung der Depression (vg1. Elkin, 1994) deuteten auf eine ausgeprägtere Reduktion in der Therapiemitte ( 8 . Woche) unter Imipramin im Vergleich zu kognitiver Therapie (CBT) und interpersonaler Therapie (IPT) hin, während keine bedeutsamen Unterschiede in der Symptomreduktion zwischen diesen drei Behandlungsbedingungen bei Therapieende feststellbar waren. Die hier beschriebenen Analysen von bis dato nicht analysierten Daten, die aus Therapeutenratings, klinischen Beurteilungen und Patientenbeurteilungen bei Therapieende und einer 18-Monats-Katamnese stammten, deuteten ebenfalls auf keine signifikanten Unterschiede zwischen den drei Behandlungsbedingungen bzgl. einer Symptomreduktion bzw. Beurteilungen des aktuellen klinischen Zustands. Signifikante Behandlungsunterschiede zeigten sich aber bei der 18-Monats- 
Katamnese in den Patientenbeurteilungen im Hinblick auf die Auswirkungen der Behandlingen auf die allgemeine Anpassung. Patienten in IPT berichteten von einer gröseren zufriedenheit mit der Behandlung, Patienten in IPT und CBT brachten deutich grösere Effekte der Behandhng auf ihre Fähigkeit interpersonale Beziehungen einzugehen und aufrecht zu erhalten zum Ausdnuck, ebenso im Hinblick auf die Fähigkeit, Hintergrüde ihrer Depression zu erkennen und zu verstehen als dies bei Patienten der Fall war, die mil Imipramin oder Placebo behandelr wurden.

\section{Rếsumé}

Des analyses précédentes de données du programme de recherche sponsorisé par le NIMH sur le traitement de la dépression (TDCRP ; Elkin 1994) ont indiqué une réduction de symptômes plus impotante au milieu du traitement (8ème semaine) avec l'mipramine (IMI-CM) qu'avec la thérapie cognitivo-compontementale (CBT) et la thérapie interpersonnelle (IPT), mais pas de différences significatives entre ces trois traitements actifs dans la réduction de symptomes à la fin du traitement. Des analyses actuelles de données non analysées auparavant issues de cotations des thérapeutes, des juges cliniques et des patients, à la fin et 18 mois après, indiquent également une absence de différences entre ces traitements pour la réduction des symptômes ou les cotations de l'état clinique courant. Par contre, des différences significatives entre les traitements émergeaient à la catamnèse à 18 mois dans l'évaluation des patients de l'effet du traitement sur leur adaptation dans la vie. Les patients en condition IPT ont témoigné d'une satisfaction phus grande avec le traitement, et les patients dans les conditions IPT et CBT d'effets significativement plus grands du traitement sur leur capacité à établir et à maintenir des relations interpersonnelles, et à recounaître et comprendre des sources de leur dépression, que les patients en condition IMI-CM ou placebo.

\section{Resumen}

Análisis previos de datos del Programa colaborativo de investigación del tratamiento de la depresión (Treatment for Depression Collaborative Research Program, TDCRP; e.g., Elkin, 1994), financiado por el NJMH, indicaron que existe una mayor reducción de los sintomas a mitad del tratamiento (ocho semanas) con Imipramina (IMI-CM) que con terapia cognitivo-comportamental (CBT) y terapia interpersonal (IPT), pero que no hay diferencias significativas entre estos tres tratamientos en la reducción de los sintomas a su terminación. ios análisis actuales de datos obtenidos de evaluaciones hechas por terapeutas, evaluadores clínicos y pacientes a la terminación y a los dieciocho meses de seguimiento, tampoco indicaton diferencias significativas entre estos tratamientos en cuanto a la reducción sintomática o la evaluación de la condición clinica actual. Pero a los dieciocho meses emergieron diferencias significativas entre los tratamientos en cuanto a las evaluaciones hechas por los pacientes de los efectos del tratamiento sobre su adecuación vital. Los pacientes en IPT reportaron mayor satisfacción con el tratamiento que los pacientes con IMI-CM o con placebo y, tanto en IPT como en CRT, los pacientes reportaron mejorias significativas en su capacidad de establecer y mantener relaciones interpersonales y en reconocer y comprender las fuentes de su depresión.

Received Nowember 30,1998

Revision received October 20, 1999

Accepted October 22, 1999 